\title{
The Reality of Gaza Strip Cities towards the Smart City's Concept. A Case Study: Khan Younis City
}

\author{
Abdelkhalek I. Alastal, Raed A. Salha, Maher A. El-Hallaq \\ The Islamic University of Gaza, Gaza, Palestine \\ Email: abdelkhalek.alastal@gmail.com,rsalha@iugaza.edu.ps,mhallaq@iugaza.edu.ps
}

How to cite this paper: Alastal, A. I., Salha, R. A., \& El-Hallaq, M. A. (2019). The Reality of Gaza Strip Cities towards the Smart City's Concept. A Case Study: Khan Younis City. Current Urban Studies, 7, 143-155.

https://doi.org/10.4236/cus.2019.71006

Received: March 4, 2019

Accepted: March 26, 2019

Published: March 29, 2019

Copyright $\odot 2019$ by author(s) and Scientific Research Publishing Inc. This work is licensed under the Creative Commons Attribution International License (CC BY 4.0).

http://creativecommons.org/licenses/by/4.0/

(c) (i) Open Access

\begin{abstract}
This study aims to promote sustainable urban development by adopting the smart city approach by identifying the concept of smart cities in the reality of the cities of Gaza Strip, considering Khan Younis city as a case study. It also focuses on formulating a future vision using geographic information systems (GIS) and building information modeling (BIM) using current city data and plans. For this purpose, a checklist is designed to investigate the current reality of Khan Younis towards the concept of smart cities. It consists of two parts. The first one includes the demographic data while the second part involves nine axes; the availability of institutional infrastructure, availability of physical infrastructure, availability of social infrastructure, availability of economic infrastructure, availability of smart management components, use of smart city tools, achievement of the city's 3D goals, evaluation the level of use of GIS/BIM in decision supporting, as well as assessing the degree of challenges prevent transforming towards the smart city approach. The checklist analysis reveals that Khan Younis has $41.7 \%$ of the characteristics features of the smart city and needs further improvements in all axes especially the availability of social and economic infrastructures. Thus, the study recommends training the existing cadres to enable them to use GIS/BIM technologies in transforming to smart cities. It also recommends that society be educated and equipped to ensure that it receives and uses all these things in order to achieve the goal of improving the quality of life and facilitating the daily lives of people.
\end{abstract}

\section{Keywords}

Smart City, GIS, BIM, Khan Younis, Urban Development, Checklist Analysis 


\section{Introduction}

Smart sustainable city is that uses the technology to transform their core systems and optimize the exploitation of limited resources. It is a knowledge-based system that provides real-time insights to stakeholders (Paroutis et al., 2014). Smart sustainable city is defined as a city of good performance in a forward-looking way in economics, people, governance, mobility, environment and living, built on a clever mix of self-critical attitudes and activities of self-citizens (Giffinger et al., 2007). The city's smart components vary from place to place, but there are key elements that represent the city's smart components: institutional infrastructure, physical infrastructure, social infrastructure (Ratan, 2015). The city's smart properties are concerned with all aspects of life for its residents of health, education, security and safety, transportation, water, electricity, technology, justice and equity for all members of society.

The cities of Gaza Strip face a number of challenges: the increase in population due to the increase in the birth rate, the return of Palestinian emigrants for various reasons from abroad to the cities of Gaza Strip, the increasing pressure on the resources, services, various facilities, as well as the challenges facing the cities of Gaza Strip such as weakness and erosion of infrastructure represented in the sector of water, sanitation, electricity, transport, transportation, health, educational facilities, the aggravation of environmental problems and unemployment. In addition to, the siege imposed on the site of Gaza Strip for more than ten years, as well as successive wars that destroyed the remaining infrastructure. Consequently, the cities of Gaza Strip need non-traditional solutions. One of them is to follow the smart cities approach, and to define the reality of cities in Gaza Strip from the concept of it. Thus, the goal of this study is to study the reality of the cities of Gaza Strip in terms of the concept of smart cities. For this purpose, a checklist is designed and analyzed to investigate the current reality of Khan Younis, as a case study, toward this concept.

\section{Previous Studies}

Shahi (2018) emphasizes that the integration of BIM with GIS, will allow evaluation of the construction project in its urban context, allowing many intelligent urban management applications. Abbas (2017) aims to identify the most important indicators of smart cities and their relation to transport, economy, environment, people, society, and living. He governance to compare three cities in the United States: Los Angeles, Chicago, and Houston based on these indicators of the smart city. The study shows that Chicago has the most characteristic features of the smart city, while Los Angeles and Houston need further improvement to meet the city's smart requirements. Antonsen (2017) concludes that the focus on infrastructure development is very important for the city that wants to become a smart city, because the infrastructure needs to be able to build smart initiatives for the city. Freeman (2017) shows that the smart cities model of sustainable development could provide opportunities to engage a variety of actors 
in finding solutions to the most important and most pressing challenges to sustainability in the city. Carnevale (2017) aims to provide government open data to citizens in an attractive and educational manner that can help citizens to participate in public affairs. Jessen (2015) also aims to promote investment in technology and human and social capital side by side and achieve this through participatory governance. Kogan (2014) indicates that the most important variable that can determine the success of a smart city project is the participation of citizens, while governance and, Information and Communication Technology, ICT are ranked next. The various integration efforts of BIM and GIS models are addressed in (El-Mekawy, 2010) where it shows that BIM data can be automatically integrated and processed in different kinds.

The previous studies are varied and of great benefit to the subject of the study and highlight the need for further studies of smart cities and sustainable urban development. They all deal with cities and regions that differ in their nature, potential, geographic location, political, economic, social and cultural conditions than this study area, as well as it can be said that the needs are also different from the needs of this study area. Hence, this study will contribute to finding information that has not been reached in previous studies.

\section{The Study Area}

Khan Younis is in the southwestern part of Palestine, south of Gaza City. It is also a part of the eastern coast of the Mediterranean Sea, $25 \mathrm{~km}$ south of Gaza city and $20 \mathrm{~km}$ from the Egyptian-Palestinian border, Figure 1.

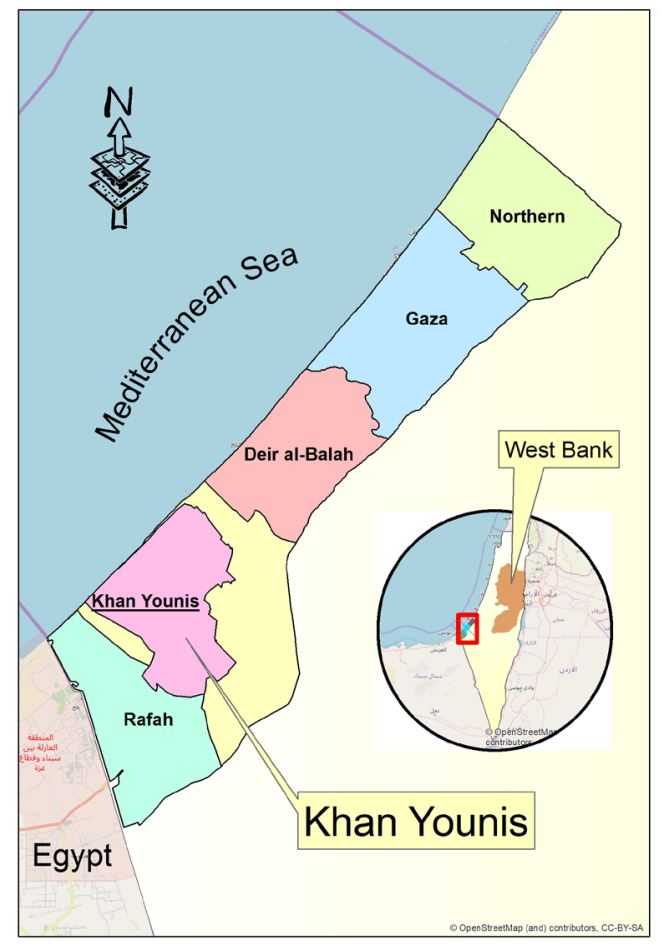

Figure 1. The geographic location of Khan Younis city. 
The city of Khan Younis is about $54 \mathrm{~km}^{2}$. According to the Central Bureau of Statistics, the population of Khan Younis is 351,934 by the end of 2016 (PCBS, 2017). Infrastructure in Khan Younis city faces many challenges in terms of water, sanitation, electricity, health, and education. Others are in terms of reconstruction and maintenance areas, the continued provision of services to citizens due to the embargo, lack of funding as well as increased pressure on resources. Khan Younis is selected as a case study since it is considered the largest city in terms of area and its population represent one fifth of the total population of Gaza Strip.

\section{The Checklist Design}

The checklist on the subject of "Enhancing Sustainable Urban Development through the Smart City using GIS \& BIM: A Case Study: Khan Younis city" is designed. The checklist targets engineers from Khan Younis municipality, officials from Ministry of Housing, academic professors, as well as stakeholders from private sector engaged in engineering. Fifty samples are randomly distributed, and forty-seven are recovered. The checklist consists of two parts. The first part involves the demographic data such as qualification, age, workplace, job title, nature of work, type of project, use of the GIS/BIM system, experience of use of the GIS/BIM system, organization's desire to adopt the GIS/BIM system, possibility of replacing the GIS/BIM system with CAD system, and BIM project size link. On the other hand, the second part consists of nine axes:

- First: availability of institutional infrastructure, 9 paragraphs.

- Second: availability of physical infrastructure, 18 paragraphs.

- Third: availability of social infrastructure, 13 paragraphs.

- Fourth: availability of economic infrastructure, 10 paragraphs.

- Fifth: availability of smart management components, 13 paragraphs.

- Sixth: use of smart city tools, consisting of 9 paragraphs.

- Seventh: achievement of the city's 3D goals and benefits, 10 paragraphs.

- Eighth: evaluation level of use of GIS/BIM in decision supporting, 7 paragraphs.

- Ninth: Assessment of challenges prevents transforming towards the smart city approach, consisting of 7 paragraphs.

The veracity of the checklist has been verified by content validity and internal consistency using the Spearman correlation coefficient. Structural validity has also been achieved where structural validity is a measure of the validity of a tool that measures the extent to which the objectives of the instrument are achieved. The reliability of the checklist is also verified by the Cronbach's Alpha coefficient. Statistical processes used in this study are:

- Frequency and percentages to describe the study sample.

- Arithmetic mean and relative arithmetic mean.

- Alpha Cronbach test to check the stability of the checklist.

- Kolmogorov-Smirnov test to determine whether data follow normal distribu- 
tion.

- Spearman Correlation Coefficient to measure the relationship between two variables and to calculate the internal consistency and structural integrity of the checklist as well as to examine the relationship between the checklist domains.

- The Sign test is one of the nonparametric tests to determine if the average response has reached the average score of 6 , or more or less.

- Mann-Whitney nonparametric test, for two independent samples, to find out if there are significant differences between two sets of independent data.

- Kruskal-Wallis nonparametric test to determine whether there are statistically significant differences between three or more sets of data.

\subsection{Statistical Measures}

The correlation between some checklist hypotheses is shown in Table 1 . The Sig. level for all is .000 and less than $\alpha=.05$ level. This indicates a statistically significant relationship where the extent of low utilization of BIM/GIS systems is evident and hence the need to develop the performance of the institutional infrastructure, which is weak that needs to be addressed. It also illustrates the degree of decline of city use of GIS/BIM systems as well as the need to adopt and use these systems to develop and improve the physical infrastructure. In addition to, the low use of GIS/BIM systems which we need to use for development and promotion of social infrastructure.

The Mann-Whitney nonparametric test is used for two independent samples to determine if there are statistically significant differences. This test compares two sets of data. The Kruskal-Wallis nonparametric test is used to determine whether there are statistically significant differences as this test compared three or more averages. Table 2 shows that the probability level (Sig.) is less than the significance of $\alpha=.05$ for most of the demographic variables except for 9 and 11 paragraphs. It can therefore be concluded that there are statistically significant differences between the average responses of respondents to the "institutional

Table 1. Correlation between some checklist hypothesis.

\begin{tabular}{ccl}
\hline Sig. Level & $\begin{array}{c}\text { Spearman } \\
\text { Correlation }\end{array}$ & \multicolumn{1}{c}{ Hypothesis } \\
\hline $.119^{*}$ & $\begin{array}{l}\text { There is a statistically significant relationship at } \alpha=.05 \text { level } \\
\text { between the "institutional infrastructure" and the "use of smart } \\
\text { management components: GIS/BIM in transition to smart cities" } \\
.000\end{array}$ \\
$.218^{*}$ & $\begin{array}{l}\text { There is a statistically significant relationship at } \alpha=.05 \text { between } \\
\text { "physical infrastructure" and "use of smart management } \\
\text { components: GIS/BIM in transition to smart cities". }\end{array}$ \\
& $\begin{array}{l}\text { There is a statistically significant relationship at the } \alpha=.05 \\
\text { level between "social infrastructure" and "use of smart } \\
\text { management components: GIS/BIM in transition to smart cities" }\end{array}$ \\
\hline
\end{tabular}

${ }^{*}$ correlation statistically at significance level $\alpha=.05$. 
Table 2. Kruskal-Wallis and Mann-Whitney for "institutional infrastructure" and demographic variables.

\begin{tabular}{lcccc}
\hline S. & Demographic data & Test name & Test value & Sig. \\
\hline 1 & Scientific qualification & Kruskal-Wallis & 67.279 & .000 \\
2 & Age & Kruskal-Wallis & 205.428 & .000 \\
3 & Workplace & Kruskal-Wallis & 206.341 & .000 \\
4 & Job title & Kruskal-Wallis & 361.863 & .000 \\
5 & Work nature & Kruskal-Wallis & 112.381 & .000 \\
6 & Type of projects implemented & Kruskal-Wallis & 141.688 & .000 \\
7 & Knowledge of the BIM system & Kruskal-Wallis & 8.436 & .015 \\
8 & Organization use BIM system & Mann-Whitney & $45,928.5$ & .000 \\
9 & Years use BIM system & Kruskal-Wallis & .325 & .569 \\
10 & The organization's desire to adopt the BIM system & Mann-Whitney & 112,921 & .000 \\
11 & Replace BIM with CAD & Mann-Whitney & 144,340 & .538 \\
12 & Link BIM system utility with project size & Mann-Whitney & 115,064 & .000 \\
\hline
\end{tabular}

infrastructure". In order to determine the differences between the averages attributed to any group within the variables in which the Kruskal-Wallis test is performed, the Mann-Whitney test reveals that the differences between averages are attributed to all categories.

\subsection{Demographic Data Analysis}

The demographic data results are summarized in Figure 2. Figure 2(a) shows that $28.6 \%$ of the sample holds the postgraduate degree, $69 \%$ holds the bachelor's degree and only $2.4 \%$ holds a diploma degree. This means that Khan Younis city has scientifically qualified cadres to implement the smart city project.

Figure 2(b) shows that $45.2 \%$ of the sample is less than 30 years old. This means that the technical staff is young and dependable to achieve the aspirations of implementing the smart city project. Figure 2 (c) shows that $33 \%$ of the sample does not know the BIM system, $61.9 \%$ know it but not in use and $4.8 \%$ is a real user. This is a clear indication of the low interest in BIM systems, technologies, deployment and use. This represents a weakness point, as well as the need to address this situation by qualifying human cadres in this area.

Figure 2 (d) shows clearly that $97.6 \%$ of the sample uses the BIM system for number of years ranging from zero to one year. This indicates the lack of experience in this area, which also means a weak point, which calls for more attention to this area.

As can be observed in Figure 2(e), 52.4\% of targeted enterprises wish to adopt the BIM system while up to $42.9 \%$ have no desire. This means that there is a fairly solid base can be transformed into modern BIM technology, which is important and fundamental in switching to smart cities. The city has the solid institutional base of the start in the smart civil project and represents a point of strength that can be strengthened. 


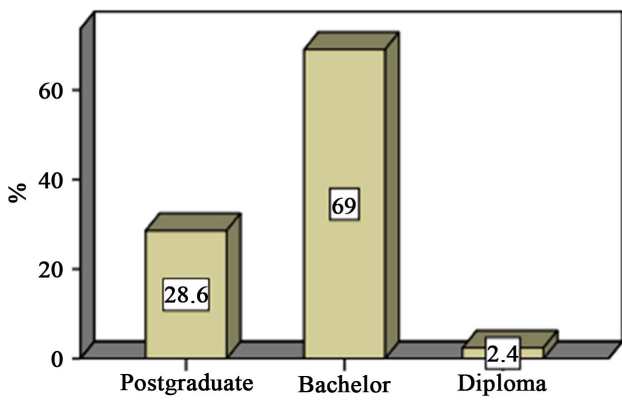

(a)

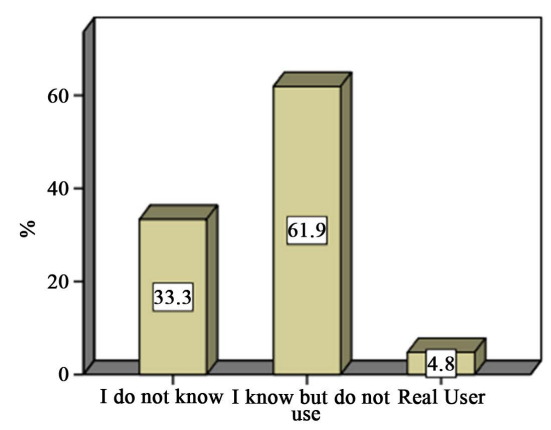

(c)

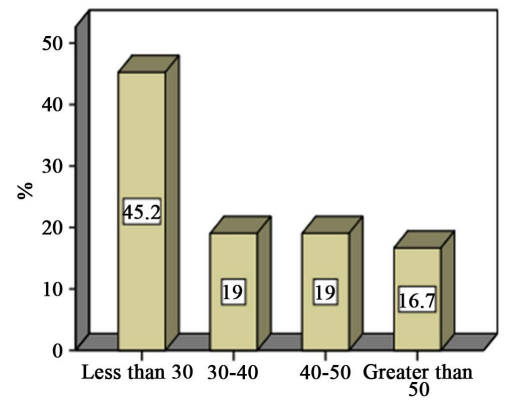

(b)

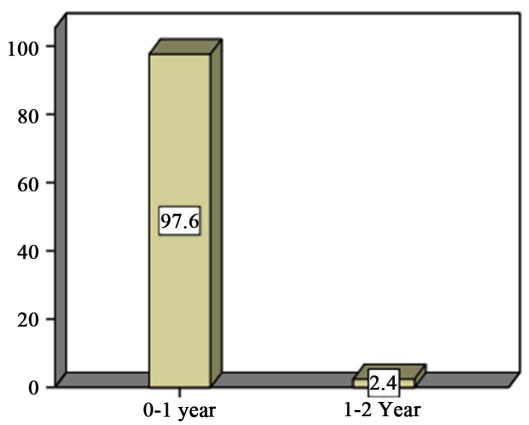

(d)

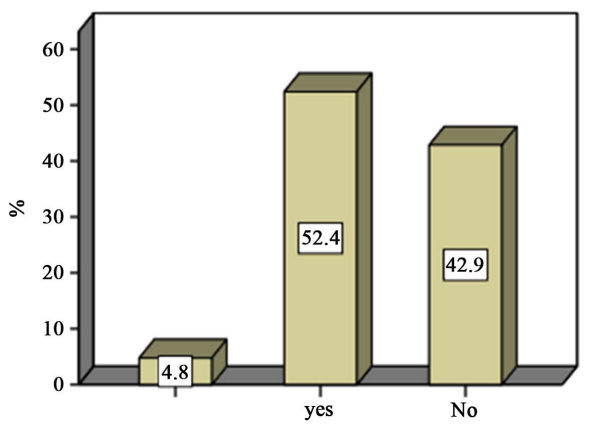

(e)

Figure 2. The demographic data analysis; (a) qualification; (b) age; (c) knowledge of the BIM system; (d) experience with BIM system and (e) Institutions wishing to adopt the BIM system.

\subsection{Analysis of Checklist Paragraphs}

The Signal test is used to analyze the paragraphs of each of the nine axes of the checklist, which is a nonparametric test because the data do not follow the normal distribution to determine whether the average response has reached a neutral level of 6 or not. Here is an example of the analysis process done using the Sign test for the first axis. This example is to test the availability of institutional infrastructure. The results are shown in Table 3.

Table 3 indicates that the highest rank in this field is paragraph 9, which states that "communication with citizens is through the means of the Internet". It is ranked first with an average of 7.10 , total score of 10 , and $71 \%$ of relative weight. The significance is .000 , which means that there is approval by the respondents on this paragraph. The lowest rank in this area is paragraph 2, which 
Table 3. Signal test results for "Institutional Infrastructure" axis.

\begin{tabular}{|c|c|c|c|c|c|}
\hline S. & Paragraphs & Mean & $\begin{array}{l}\text { Relative } \\
\text { weight \% }\end{array}$ & $\begin{array}{l}\text { P Value } \\
\text { (Sig.) }\end{array}$ & Ranking \\
\hline 1 & $\begin{array}{l}\text { Legislation and laws in government institutions } \\
\text { are in line with developments in society. }\end{array}$ & 5.97 & 59.7 & $.000 \mathrm{a}$ & 6 \\
\hline 2 & $\begin{array}{l}\text { Legislation and laws are flexible to meet the } \\
\text { needs of society through sustainable development. }\end{array}$ & 5.44 & 54.4 & $.000 \mathrm{a}$ & 9 \\
\hline 3 & $\begin{array}{l}\text { The institutions have equipment and qualified } \\
\text { trained technical staff to use modern technologies. }\end{array}$ & 6.14 & 61.4 & $.000 \mathrm{a}$ & 5 \\
\hline 4 & $\begin{array}{l}\text { Information and communication technologies } \\
\text { are used to deliver services to residents of the city. }\end{array}$ & 6.73 & 67.3 & $.551 \mathrm{a}$ & 3 \\
\hline 5 & $\begin{array}{l}\text { Accurate, quality, transparent and accessible } \\
\text { information is available to all segments of society. }\end{array}$ & 5.62 & 56.2 & $.000 \mathrm{a}$ & 7 \\
\hline 6 & $\begin{array}{l}\text { The availability of such information helps to } \\
\text { achieve sustainable development. }\end{array}$ & 6.92 & 69.2 & $.000 \mathrm{a}$ & 2 \\
\hline 7 & $\begin{array}{l}\text { Participation between government and private } \\
\text { sector and involvement of society in decision-making. }\end{array}$ & 5.45 & 54.5 & $.000 \mathrm{a}$ & 8 \\
\hline 8 & $\begin{array}{l}\text { Communication between government agencies and } \\
\text { the private sector is conducted through the Internet. }\end{array}$ & 6.48 & 64.8 & $.000 \mathrm{a}$ & 4 \\
\hline \multirow[t]{2}{*}{9} & Communication with citizens through the Internet. & 7.10 & 71.0 & $.000 \mathrm{a}$ & 1 \\
\hline & All paragraphs of the axis. & 5.58 & 55.8 & $.000 \mathrm{a}$ & \\
\hline
\end{tabular}

a. Based on Z Approximation.

states that "the legislation and laws are flexible to meet the needs of society through sustainable development". Its rank is the last with an average of 5.44. The level of significance is .000 , which means that there is no approval by the sample members on this paragraph.

To evaluate all paragraphs in this axis, the mean value is 5.58 , Figure 3 , the relative weight is $55.8 \%$, and the significance level is .000 . Therefore, the null hypothesis is rejected, and the alternative hypothesis is accepted that the average rating of the sample differs significantly from the average approval. Thus, the field of "institutional infrastructure" is statistically significant at $\alpha=.05$ and differs from the average approval level of 6 . This means that there is disagreement by the sample members on the paragraphs of this field.

Table 4 summarizes the Sig. test result of the checklist axis. It shows that the average for all paragraphs in all axes is 4.17 , total score of 10 , with a relative weight of $41.7 \%$ and the significance level is .000 . Therefore, all the paragraphs are statistically significant at $\alpha=.05$. It is essentially different from the degree of neutrality which is 6 . Thus, it indicates that the respondents did not agree to the paragraphs in general. This means that the concept of a smart city in all axes is achieved at a rate of $41.7 \%$. 


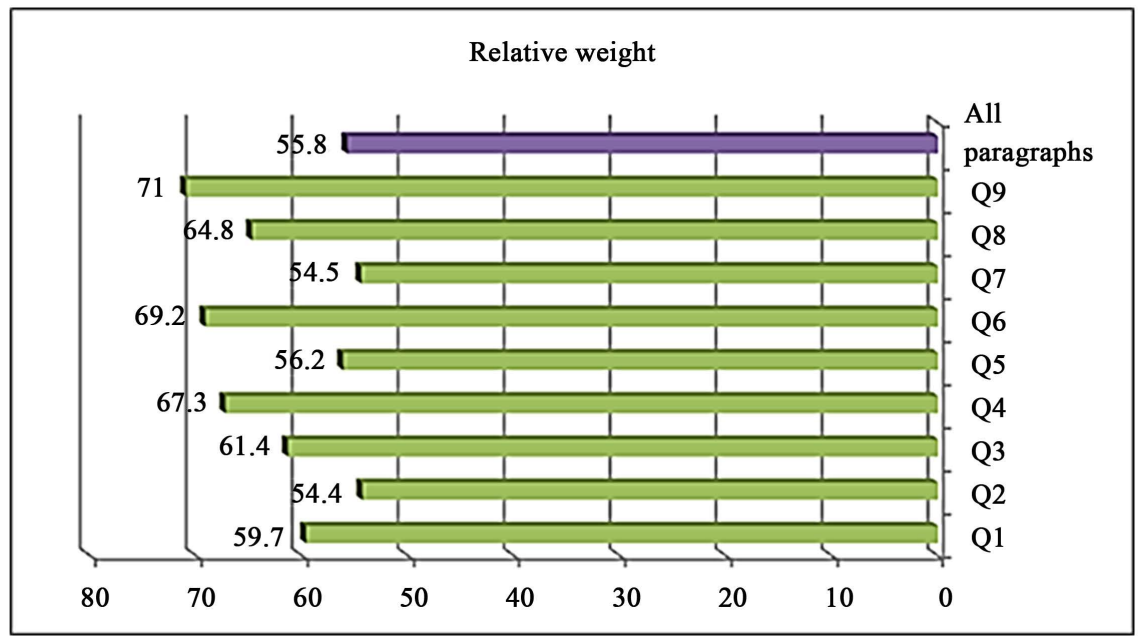

Figure 3. Relative weight field of "institutional infrastructure".

Table 4. The Sig. test results for all axes of the checklist.

\begin{tabular}{ccccc}
\hline S. & Axes & Mean & Relative weight $\%$ & P Value (Sig.) \\
\hline 1 & institutional infrastructure & 5.58 & 55.8 & $.000 \mathrm{a}$ \\
2 & physical infrastructure & 7.70 & 77.0 & $.000 \mathrm{a}$ \\
3 & social infrastructure & 5.98 & 59.8 & $.000 \mathrm{a}$ \\
4 & economic infrastructure & 3.50 & 35.0 & $.000 \mathrm{a}$ \\
5 & smart management components & 4.77 & 47.4 & $.000 \mathrm{a}$ \\
6 & smart city tools & 4.06 & 40.6 & $.000 \mathrm{a}$ \\
7 & city's 3D goals and benefits & 3.62 & 36.2 & $.000 \mathrm{a}$ \\
8 & level of use of GIS/BIM & 2.92 & 29.2 & $.000 \mathrm{a}$ \\
9 & challenges towards smart approach & 4.83 & 48.3 & $.000 \mathrm{a}$ \\
& All axes & 4.17 & 41.7 & $.000 \mathrm{a}$ \\
\hline
\end{tabular}

a. The mean is statistically significant at $\alpha=.05$.

\subsection{Discussion of Checklist Results}

The checklist results reveal strength and weakness points corresponding the degree of smart city achievement of Khan Younis. The strength points involve:

- The most important strength is the human capital of the city. The study shows that $28.6 \%$ of the sample has a postgraduate degree, $69 \%$ have a bachelor's degree, and only $2.4 \%$ have a diploma. This means that Khan Younis has scientifically qualified cadres to implement smart city project.

- The study also shows that $45.2 \%$ of the study sample is less than 30 years, which means that the technical staff are young people, whom can be relied upon to achieve the aspirations in the implementation of the smart city project.

- The study also shows that government institutions represent $42.9 \%$ of the sample and private establishments $28.6 \%$, equivalent to $71.5 \%$. This means 
that the city's institutional infrastructure has the capacity to start the smart city, as well as university academics who can contribute effectively and play an important role in the smart city project.

- Institutions that wish to adopt the BIM system are up to 52.4\%, which do not want $42.9 \%$. This means that there is a solid basis can be transformed into modern BIM technology, which are important and essential in the transformation to smart city. This means that the city has a solid institutional base to start in the smart city project.

On the other hand, the weakness points involve:

- The study shows that specialists in the field of BIM are $2.4 \%$, which means that there is a significant reduction in the specialization related to BIM technology, which is a modern technology and important in the field of smart cities, and technical staff need to be qualified in this field to be able to implement the requirements of the city smart highly efficient.

- The study illustrates that $33 \%$ of the sample has no knowledge of the BIM system, while $61.9 \%$ knows but do not use it, and only $4.8 \%$ is an actual user. This is a clear indication of the low interest in BIM and its spread and use, as well as; the need to address this situation to qualify human cadres in this area.

- The study shows that $97.6 \%$ of the sample uses the GIS/BIM system for a period ranging from zero to one year. This indicates the lack of experience in this area; which requires more attention to this field.

- The institutional dimension of the infrastructure is one of the weakest points where the study shows that the relative weight of this dimension is (55.8\%).

- Economic infrastructure is also a weak point, where the study shows that the relative weight of this dimension is (35\%).

- As for the components of smart management in Khan Younis, the relative weight was $47.7 \%$.

- Regarding the use of GIS/BIM techniques for design, planning and decision-supporting purposes has a relative weight of $40.6 \%$.

- Finally, the level of use of GIS/BIM systems is not as deep as to meet with the smart city need since the result of this axis is $29.2 \%$.

\section{Conclusion and Recommendations}

Gaza Strip faces multiple problems of limited space, continuous population growth, and the depletion of already scarce natural resources. In addition to the siege imposed by the occupation and successive wars, all these problems require proper planning and rational use of resources. Thus, the integrated features and capabilities offered by BIM and GIS technologies make it an important and effective role in managing assets and resources with efficiency and high quality. Urban services will therefore be more efficient, and the cities of Gaza Strip will be more able to achieve sustainable development and competition in difficult economic, environmental and social conditions. Therefore, urban services will 
be more efficient, and the cities of Gaza Strip will be able to achieve sustainable development and competition in difficult economic, environmental and social conditions. The checklist analysis for Khan Younis, as an example, reveals that there is a strong need for a continuous effort to match the smart city concept since the overall achievement weight is about $41 \%$. Most of the components of smart cities are not available and its weight is down the average. Based on this study results, it is recommended to: First, training the existing cadres to enable them to use GIS/BIM technologies in transforming to smart cities that represent the city's human capital; Second, educating and preparing the community with all technologies, applications and sustainability processes to ensure the good reception and use of all these things in order to achieve the goal of improving the quality of life and facilitating the daily lives of people; Third, using the GIS and BIM mainly to contribute in the transformation of smart cities through:

- Collecting spatial and descriptive data.

- Digitizing of plans to achieve comprehensiveness and avoid repetition.

- Building and managing a three-dimensional geometric descriptive database of the city that includes various elements of the city of buildings, services and facilities, benefiting the city's stakeholders from governmental and private institutions, as well as citizens to provide them with a clear vision of effective policies and best practices and support decision-making.

- Continuous monitoring of all aspects of the sustainable development process.

- Providing access to effectively open data to all stakeholders in development.

- Infrastructure and Facilities Management: Due to the availability of a centralized, geographically integrated database of all elements of the city, the infrastructure of the city and its facilities can be managed efficiently and effectively through evaluation, follow-up, maintenance and service delivery, significantly reducing resource waste; thus, controlling quality to improve quality of life population.

- Achieving the three-dimensional perception of the current situation in the city and developing sustainable and innovative future scenarios based on the city's current data, current plans, proposals and project requirements.

- Performing analysis using geographic information systems (GIS), mapping of environmental impacts, and city data by combining standard model outputs with the 3D GIS database.

- Establishing an interactive three-dimensional portal based on GIS for citizen participation and a leadership panel to support the decision of the city government.

- Providing a three-dimensional environment for planners and decision-makers in the city, including tools that allow clear presentation of new projects and scenarios for urban development, and allow citizen participation and promotion.

Based on the above, it is possible to say that data, techniques and applications with all its elements play a key role in the transformation of the traditional city 
into a smart city and by managing the three elements intelligently, professionally and continuously to become a permanent lifestyle that allows access to the desired results. It is therefore possible to say that the human element is the decisive factor in the process of smart transformation according to the local, regional and international conditions surrounding the city, as well as according to the economic, social and political potential of the city. In the end, it can be said that the city is forced or willing to follow the path of scientific and technical development in order to survive.

\section{Conflicts of Interest}

The authors declare no conflicts of interest regarding the publication of this paper.

\section{References}

Abbas, R. (2017). A Comparison of Smart City Indicators for Three Top Ten US Cities. Master Thesis, Arlington, VA: The University of Texas. https://rc.library.uta.edu/uta-ir/bitstream/handle/10106/26843/ABBAS-THESIS-2017.p df?sequence $=1$ \&isAllowed $=\mathrm{y}$

Antonsen, H. (2017). Platform Infrastructure as a Driver of Smart City Development. Master Thesis, Oslo: University of Oslo.

https://www.datek.no/dv-cms/resources/masterhaakoaan-1.pdf

Carnevale, M. J. (2017). Toronto Augmented Reality Map: Enhancing Citizen Engagement with Open Government Data Using Contemporary Media Platforms. Master Thesis, OCAD University. http://openresearch.ocadu.ca/id/eprint/1680/

El-Mekawy, M. (2010). Integrating BIM and GIS for 3D City Modeling the Case of IFC and CityGML. Master Thesis, Stockholm: Royal Institute of Technology (KTH).

Freeman, G. (2017). The Origin and Implementation of the Smart-Sustainable City Concept the Case of Malmö-Sweden. Master Thesis, Lund University, University of Manchester and University of the Aegean.

Giffinger, R., Fertner, C., Kramar, H., \& Meijers, E. (2007). Smart Cities Ranking of European Medium-Sized Cities (p. 11). Vienna, UT: Centre of Regional Science. http://www.smart-cities.eu/download/city_ranking_final.pdf

Jessen, J. (2015). How to Create a Smart City? Co-Creation of a Smart City with Citizens. Master Thesis, Eindhoven University. http://www.digitalbydel.dk/wp-content/uploads/2015/01/MA_Guenter_final.pdf

Kogan, N. (2014). Exploratory Research on Success Factors and Challenges of Smart City Projects. Master Thesis, Seoul: Kyung Hee University. https://bci.inap.es/alfresco_file/5179cdb0-7c0d-4ecf-a0c2-21c7ed3bb170

Palestinian Central Bureau of Statistics, PCBS (2017). Statistical Yearbook of Palestine (No. 18). Ramallah. http://www.pcbs.gov.ps/default.aspx

Paroutis, S., Bennet, M., \& Heracleous, L. (2014). A Strategic View on Smart City Technology: The Case of IBM Smarter Cities during a Recession. Technological Forecasting and Social Change Journal, 89, 262-272. https://doi.org/10.1016/j.techfore.2013.08.041

Ratan, N. (2015). Making Cities Smart and Sustainable. Price Water House Coopers Private Limited.

https://www.pwc.in/assets/pdfs/publications/2015/making-cities-smart-and-sustainabl 
A. I. Alastal et al.

e.pdf

Shahi, K. (2018). Evaluation of Current Construction Permitting Process in City of Toronto and Future of Permitting in the Global Construction Industry. Master Thesis, Toronto: University of Toronto. 